\title{
Papers
}

\section{Immunohistochemical evaluation of keratin 20 expression in intestinal metaplasia types I to III}

\author{
M J Schwerer, K Baczako
}

\begin{abstract}
Aims-To investigate differences in expression of keratin 20 , a cytoskeletal protein in gastrointestinal epithelial cells, in completely differentiated intestinal metaplasia (type I) and incomplete metaplasia (types II and III).

Methods-Gastric biopsy specimens from 66 patients with intestinal metaplasia were analysed immunohistochemically. Expression of keratin 20 was quantified as the percentage of immunoreactive cells on the tips, the upper, and deep foveolae. Results-In all specimens keratin 20 was found on the tips and in the upper foveolae of intestinal metaplasia. Keratin 20 was not observed in the deep foveolae. No differences were seen between the antrum and the body. Expression patterns were comparable between types I and III. In type II, however, lower immunoreactivity was found. Both the differences between types $I$ and II as well as between types II and III were significant $(p<0.05)$. Conclusions-Keratin 20 is expressed in metaplastic mucosa as a result of intestinal differentiation. Positive staining found exclusively in juxtaluminal cells occurs only in mature cells containing keratin 20. Lowered immunoreactivity in type II compared with types I and III indicates the different nature of type $I I$ intestinal metaplasia. Further studies are needed to shed light on the basic fundamental mechanism responsible for this. ( Clin Pathol 1996;49:791-794)
\end{abstract}

Keywords: keratin 20, immunohistochemistry, intestinal metaplasia types I, II, III.

Institute of Pathology, Ulm/Donau, Germany M J Schwerer K Baczako

Correspondence to: Dr Karl Baczako, Institute of Pathology, PO Box 3260, D-89022 Ulm/Donau, Germany.

Accepted for publication 4 June 1996
The gastric mucosa is a polar organised tissue formed from a glandular part, a stem cell compartment near the isthmus, as well as surface epithelium. It comprises distinct areas-the foveolae and the tips. ${ }^{1}$ It is formed from high, slender cells secreting abundant neutral, periodic acid Schiff positive mucins. ${ }^{12}$ In chronic gastritis several changes occur in the gastric mucosa. ${ }^{34}$ Intestinal metaplasia is one of the most common, occurring in up to $25 \%$ of biopsy specimens showing chronic gastritis in developed countries. ${ }^{5-7}$ It is characterised by intestinal features which are morphologicalgoblet cells - as well as histochemical, such as acidic mucins and/or the occurrence of brush border enzymes such as alkaline phosphatase. ${ }^{5-10}$ According to these markers, different types of intestinal metaplasia have been classified using conventional histochemistry. ${ }^{11}$ Only type I is completely differentiated; types II and III show incomplete differentiation. ${ }^{11}$

Recently, metaplastic and neoplastic changes in the stomach have increasingly been assessed using immunohistochemisty. ${ }^{12-15}$ Only antigens present in all types of intestinal metaplasia, however, were described in these studies. Reliable markers for the immunohistochemical distinction between types I to III have not yet been evaluated. The expression of keratin 20 as a 46 kilodalton component of intermediate filaments in gastrointestinal epithelial cells ${ }^{16}$ was investigated in types I to III intestinal metaplasia especially with regard to the difficulty of gaining reliable markers for appropriate distinction.

\section{Methods}

Gastric biopsy specimens from 66 patients ( 37 men, 29 women; age range 35-72 years; median 57 years) with chronic gastritis and intestinal metaplasia were analysed. At least four biopsy specimens from both the antrum and the body were studied from each patient. Routine histology included haematoxylin and eosin staining as well as Warthin-Starry silver staining. Gastritis was classified according to the Sydney classification system. ${ }^{17}$ In each case Helicobacter pylori colonisation of the epithelium was confirmed. Specimens showing ulcers, dysplasia, or carcinoma were excluded from the study. Sections were further examined using the periodic acid Schiff reaction, and alcian blue, $\mathrm{pH}$ 2.5, staining/high iron diamine staining. ${ }^{1819}$

CLASSIFICATION OF INTESTINAL METAPLASIA Intestinal metaplasia was classified as types I, II, and III. Type I (completely differentiated) is characterised by goblet cells secreting acidic mucins, Paneth cells, and mature, non-mucous secreting absorptive cells. Type II (incomplete differentiation) shows goblet cells with acidic 
Table 1 Cells positive for keratin 20 (\%) in type I intestinal metaplasia (median). No difference was found between the antral and body regions

\begin{tabular}{lccccc} 
& \multirow{2}{*}{ Antrum $(n=28)$} & & \multicolumn{2}{l}{ Body $(n=31)$} \\
\cline { 2 - 3 } \cline { 5 - 6 } & Goblet cells & Enterocytes & & Goblet cells & Enterocytes \\
\hline Tips & 100 & 100 & & 100 & 100 \\
Upper foveolae & 63 & 71 & & 84 & 0 \\
Deep foveolae & 0 & 0 & & 0 & 0 \\
\hline
\end{tabular}

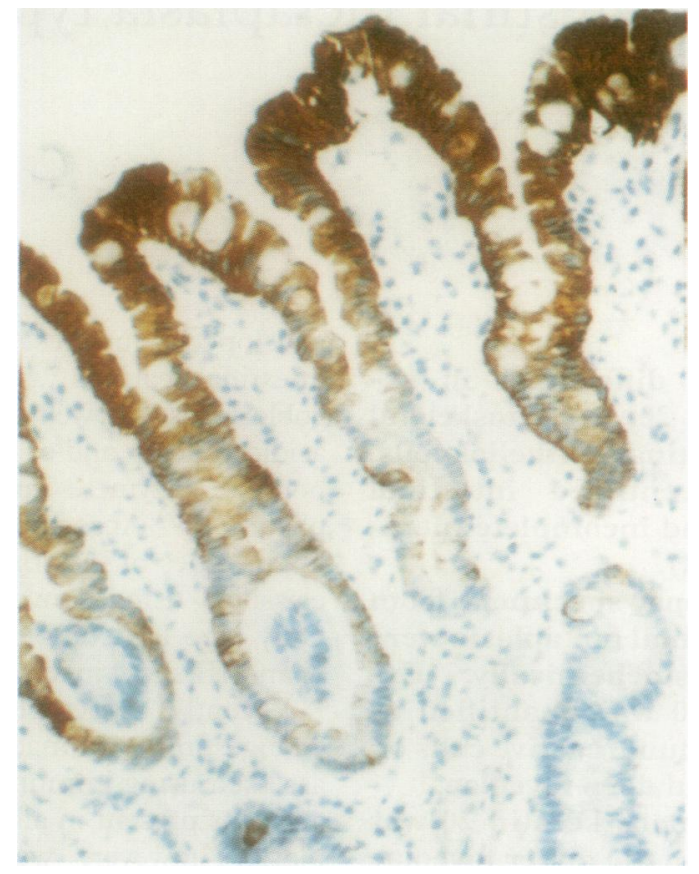

Figure 1 Keratin 20 in complete intestinal metaplasia (type I). Note abundant immunoreactivity both on the tips and in the upper foveolae. There was no positive staining in the deep foveolae.

mucins, the absence of Paneth cells, and absorptive cells, but it has columnar mucous cells secreting non-sulphated mucins. Type III (incomplete differentiation) resembles type II, but is characterised by the columnar mucous cells secreting abundant sulphomucins..$^{5-7} 11$

Type I was seen in 31 , type II in 19, and type III in 16 specimens. Biopsy specimens were classified by two observers. Differences between their independent reports were resolved by consensus.

\section{IMMUNOHISTOCHEMISTRY}

Specimens were further analysed by immunohistochemical staining of keratin 20. Sections were dried at $37^{\circ} \mathrm{C}$ for eight hours and dewaxed in xylene and rehydrated with graded alcohol and distilled water. Antigen retrieval was done using pronase in combination with microwave oven heating. ${ }^{20}{ }^{21}$ Following incubation for 10 minutes in phosphate buffered saline (PBS) at $\mathrm{pH} \mathrm{7.4,} \mathrm{endogenous} \mathrm{peroxidase}$ was blocked irreversibly using $1 \%$ (v/v) hydrogen peroxide (by dilution from $100 \mathrm{vol}$ ) in $70 \%$ (v/v) aqueous methanol for five minutes. This was followed by washing with PBS and incubation with avidin and biotin (Vector Laboratories Inc., Burlingame, California, USA) and with horse serum albumin (Vector) for $10 \mathrm{~min}$ utes. After incubation with the antibody IT-Ks 20.8 (Progen, Heidelberg, Germany) for one hour, sections were washed with PBS and coated with the avidin-biotin-peroxidasecomplex (Vectastain Elite ABC kit, mouse IgG; Camon Labor-Service GmbH, Wiesbaden, Germany) for 10 minutes. After washing with PBS, staining was performed with chromogen क 3-amino-9-ethylcarbazol (AEC, with $0.1 \mathrm{M} \vec{\circ}$ acetate buffer solution, $\mathrm{pH}$ 5.2, and $30 \%$ hydrogen peroxide; Sigma Chemical Co., $\vec{\omega}$ Deisenhofen, Germany) for 10 minutes. Each incubation was carried out in the dark chamber at $37^{\circ} \mathrm{C}$. Finally, the sections were counter- $\overrightarrow{0}$ stained with Mayer's haemalum, washed with $\overrightarrow{0}$ tap water, and mounted in glycerin gelatine.

Negative controls were stained using normal horse serum at the same dilution.

For positive controls, specimens from three adenocarcinomas of the colon as well as corresponding, tumour-free intestinal mucosa, located at least $10 \mathrm{~cm}$ distant from the tumour, were used. Positive staining with IT-Ks 20.8 was seen both in neoplastic and non-neoplastic mucosa. ${ }^{22}$

Expression of keratin 20 was quantified as the percentage of immunoreactive cells on the tips, the upper, and deep foveolae. Goblet cells (types I to III), enterocytes (type I), and columnar cells (types II and III) were examined, respectively. Specimens from the antrum and the body were investigated in individual groups.

Statistics were compiled using the Wilcoxon test for non-matched pairs. Significance was set at $\mathrm{p}<0.05$. $^{23}$

\section{Results}

Keratin 20 was found in all specimens of intestinal metaplasia. Immunoreactivity was restricted to the tips and the upper foveolae. In the deep foveolae positive staining was not seen. No differences were found between the antrum and the body.

Positive staining was observed in $100 \%$ of 0 the cells on the tips (table 1). In the upper 0 foveolae the median immunoreactivity of the cells ranged from $63 \%$ to $84 \%$ (fig 1 ).

In type III, expression rates were comparable with those of type I: $100 \%$ immunostaining on the tips, and in the upper foveolae $48.5-62 \%$ of

Table 2 Cells positive for keratin 20 (\%) in types II and III intestinal metaplasia (median). In type II expression rates were significantly lower compared with types 1 and III (see table 1)

\begin{tabular}{|c|c|c|c|c|c|c|c|c|}
\hline & \multicolumn{4}{|c|}{ Type II intestinal metaplasia } & \multicolumn{4}{|c|}{ Type III intestinal metaplasia } \\
\hline & \multicolumn{2}{|c|}{ Antrum $(n=19)$} & \multicolumn{2}{|c|}{$\operatorname{Body}(n=16)$} & \multicolumn{2}{|c|}{ Antrum $(n=16)$} & \multicolumn{2}{|c|}{$\operatorname{Body}(n=13)$} \\
\hline & Goblet cells & Columnar cells & Goblet cells & Columnar cells & Goblet cells & Columnar cells & Goblet cells & Columnar cells \\
\hline Tips & 69 & 52 & 58 & 71 & 100 & 100 & 100 & 100 \\
\hline Upper foveolae & 25 & 36 & 23.5 & 38 & 62 & 48.5 & 56 & 51 \\
\hline Deep foveolae & 0 & 0 & 0 & 0 & 0 & 0 & 0 & 0 \\
\hline
\end{tabular}



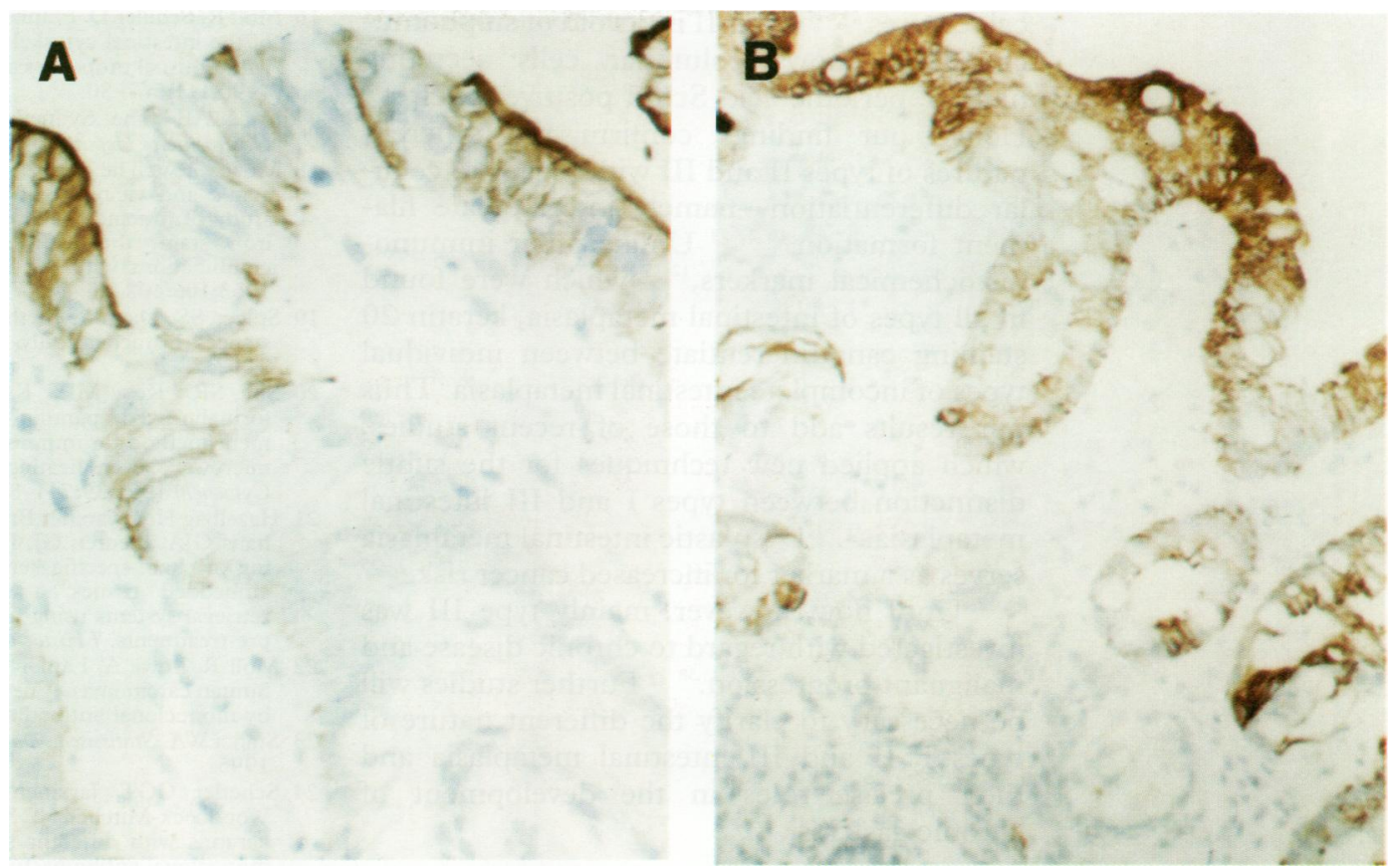

Figure 2 Keratin 20 in intestinal metaplasia showing incomplete differentiation. In type II $(A)$ expression rates were significantly lower than in types III (B) and type I (fig 1).

cells. In type II, however, lower immunoreactivity was found. This type showed median expression rates from $52 \%$ to $71 \%$ on the tips, and $23.5 \%$ to $38 \%$ in the upper foveolae (table 2 ).

The differences on the tips and in the upper foveolae between types I and II were significant ( $\mathrm{p}<0.05$; only goblet cells tested).

The difference on the tips between types II and III was significant for both goblet cells and columnar cells ( $p<0.05)$ (figs $2 A$ and $2 B$ ), and for the goblet cells in the upper foveolae ( $\mathrm{p}<0.05$ ), For the columnar cells significance was not achieved in the upper foveolae.

\section{Discussion}

We found keratin 20 in all intestinal metaplasia specimens. In general, the expression of specific keratins is closely related to certain pathways of epithelial differentiation. ${ }^{24-26}$ As reported by Moll et $a,^{16}{ }^{22}$ keratin 20 is abundantly expressed in both the stomach and intestinal surface epithelium. Hence, our observation of keratin 20 identifies intestinal metaplasia as one variant of gastrointestinal epithelial differentiation.

Immunoreactivity was restricted to the tips and the upper foveolae. In the deep foveolae, however, positive staining was not found. In the gut epithelium immature cells continuously migrate from the stem cell compartment, starting at the deep portions and rising up to the tips. ${ }^{27}$ Cellular maturation takes place during this process. Terminal differentiation is achieved as the cells reach the tips. ${ }^{27}$ Our observations imply that keratin 20 is expressed exclusively in mature cells. This agrees with recent reports of small intestinal mucosa both in animals and humans. ${ }^{28-30}$ This mechanism is the same in both the antrum and the body: no differences were seen between intestinal metaplasia in these locations.

Only type I intestinal metaplasia shows complete differentiation. ${ }^{5-7}$ We observed an abundance of keratin 20 in this type. Morphologically and histochemically, it resembles small intestinal mucosa, ${ }^{11}$ in which keratin 20 is the major cytoskeletal protein in surface epithelial cells. ${ }^{16}{ }^{28-30}$ Our findings suggest that abundant keratin 20 expression is another similarity between small intestinal mucosa and type I intestinal metaplasia.

Types II and III intestinal metaplasia display incomplete differentiation. ${ }^{5-7}{ }^{11}$ In type III, which is characterised by columnar cells secreting sulphomucins, ${ }^{11}$ we found that keratin 20 expression was similar to type I. As reported by Nardelli et al, ${ }^{31}$ type III does not resemble adult intestine, but fetal duodenum. In fetal development keratin 20 can already be detected in the intestine of the 11 week old fetus. ${ }^{32}$ Our finding of keratin 20 correlates with the suggestion that type III reflects the level of fetal differentiation.

The development of gastric cancer entails a stepwise process, including complete intestinal metaplasia (type I), followed by incomplete metaplasia (type III), and finally dysplasia and carcinoma. ${ }^{33-35}$ In general, keratin expression is highly conserved during malignant transformation. ${ }^{16222526}$ Recently keratin 20 was found in gastric carcinoma. ${ }^{36}$ Our finding of keratin 20 in types I and III corroborates this model for stomach carcinogenesis.

In contrast, we found keratin 20 significantly less often in type II than in other types of intestinal metaplasia. In general, reduced immunoreactivity present in type II is not caused by incomplete differentiation, as indicated by the difference in types II and III, which are both incomplete forms. ${ }^{11}$

Keratin 20 immunoreactivity differentiates one subgroup of incomplete metaplasia (type II) from the other (type III). Nevertheless, the basic fundamental mechanisms leading to this phenomenon remain unclear. These types used to be classified simply according to histochemi- 
cal features. ${ }^{5-711}$ Type II is devoid of sulphomucins, but shows columnar cells secreting neutral, periodic acid Schiff positive mucins. ${ }^{11}$ Hence our findings confirm the different natures of types II and III with regard to cellular differentiation-namely intermediate filament formation. ${ }^{1622}{ }^{25}$ Unlike other immunohistochemical markers, ${ }^{12-15}$ which were found in all types of intestinal metaplasia, keratin 20 staining can differentiate between individual types of incomplete intestinal metaplasia. Thus our results add to those of recent studies, which applied new techniques for the subtle distinction between types I and III intestinal metaplasia. ${ }^{37}{ }^{38}$ Dysplastic intestinal metaplasia serves as a marker for increased cancer risk. ${ }^{33-35}$ ${ }^{38} 39$ Until now, however, mainly type III was investigated with regard to chronic disease and malignant progression. ${ }^{38}{ }^{39}$ Further studies will be necessary to clarify the different nature of types I, II and III intestinal metaplasia and their precise roles in the development of chronic gastritis.

1 Owen DA. Normal histology of the stomach. Am $f$ Surg Pathol 1986;10:48-61

2 Ito S. Functional gastric morphology. In: Johnson LR, ed. Physiology of the gastrointestinal tract. New York: Raven Press, 1981:517-50.

3 Appelman HD. Gastritis: terminology, etiology, and clinicopathological correlations: Another biased view. Hum Patho 1994;25:1006-19.

4 Solcia E, Fiocca R, Villani L, Luinetti O, Gianatti A, Trespi $\mathrm{E}$, et al. The role of Helicobacter pylori in ulcerogenesis and $\mathrm{E}$, et al. The role of Helicobacter pylori in ulcerogenesis and carcinogenesis. In: Gasbarini G, Pretolani S, eds. Basic and
clinical aspects of Helicobacter pylori infection. Berlin: clinical aspects of Helicot

Craanen ME, Blok P, Dekker W, Ferwerda J, Tytgat GNJ Prevalence of subtypes of intestinal metaplasia in gastric antral mucosa. Dig Dis Sci 1991;36:1529-36.

6 Craanen ME, Blok P, Dekker W, Ferwerda J, Tytgat GNJ. Intestinal metaplasia and Helicobacter pylori: an endoscopic bioptic study of the gastric antrum. Gut 1992;33:16-20.

7 Eidt S, Stolte M. Antral intestinal metaplasia in Helicobacter pylori gastritis. Digestion 1994;55:13-18.

8 Iida F, Murata F, Nagata T. Histochemical studies of mucosubstances in metaplastic epithelium of the stomach, with special reference to the development of intestinal metaplasia. Histochemistry 1978;56:229-37.

9 Higgins PJ, Correa P, Cuello C, Liphin M. Fetal antigens in the precursor stages of gastric cancer. Oncology 1984;41: 73-6.

10 Matsukuma A, Mori M, Enjoji M. Sulphomucin-secreting intestinal metaplasia in the human gastric mucosa. An intestinal metaplasia in the human gastric mucosa. An association with

11 Jass JR. Role of intestinal metaplasia in the histogenesis of gastric carcinoma. $\mathcal{F}$ Clin Pathol 1980;33:801-10.

12 Osborn M, Mazzoleni G, Santini D, Marrano D, Martinell $G$, Weber K. Villin, intestinal brush border hydrolases, and keratin polypeptides in intestinal metaplasia and gastric cancer; an immunohistologic study emphasizing the different degrees of intestinal and gastric differentiation in signet ring Histopathol 1988;413:303-12.

13 Tahara E. Molecular mechanisms of stomach carcinogenesis. $\mathcal{F}$ Cancer Res Clin Oncol 1993;119:265-72.

14 Stemmermann G, Heffelfinger SC, Noffsinger A, Hui YZ Miller MA, Fenglio-Preisser CM. The molecular biology of esophageal and gastric cancer and their precursors: oncogenes, tumor suppressor genes, and growth factors. Hum Pathol 1994;25:968-81.

15 Craanen ME, Blok P, Dekker W, Offerhaus GJA, Tytgat GN]. Chronology of p53 protein accumulation in gastric carcinogenesis. Gut 1995;36:848-52.
16 Moll R, Schiller D, Franke WW. Identification of protein IT of the intestinal cytoskeleton as a novel type I cytokeratin with unusual properties and expression patterns. $\mathcal{F}$ Cell Bio 1990;111:567-80.

17 Price AB. The Sydney system: histological division. $f$ Gastroenterol Hepatol 1991;6:209-22.

18 Mowry RW. The special value of methods that color both acidic and vicinal hydroxyl groups in the histochemica study of mucins: with revised directions for the colloida iron stain, the use of alcian blue $8 \mathrm{GX}$ and the combinations with the PAS reaction. Ann NY Acad Sci 1963;106:402-23.

19 Spicer SS Diamine methods for differentiating mucosubstances histochemically. $f$ Histochem Cytochem 1965;13 211-34.

20 Shi SR, Key ME, Kalra KL. Antigen retrieval in formalin-fixed, paraffin-embedded tissues: an enhancement method for immunohistochemical staining based on microwave oven heating of tissue sections. $f$ Histochem Cytochem 1991;39:741-8

21 Hazelbag HM, van der Broek LJCM, van Dorst EBL Offerhaus GJA, Fleuren GJ, Hogendoorn PCW. Immunostaining of chain-specific keratins on formalin-fixed, paraffinembedded tissues: a comparison of various antigen retrieval systems using microwave heating and proteolytic pre-treatments. f Histochem Cytochem 1995;43:429-37.

22 Moll R, Löwe A, Laufer J, Franke WW. Cytokeratin 20 in human carcinomas. A new histodiagnostic marker detected by monoclonal antibodies. Am F Pathol 1992;140:427-47.

23 Stahel WA. Statistische Datenanalyse. Braunschweig: Vieweg, 1995.

24 Scheffer CGT, Jarvinen MJ, Nelson WG, Huang JW, Woodcock-Mitchell J, Sun TT. Correlation of specific Woodcock-Mitchell J, Sun TT. Correlation of specific keratins with different types of epithelial differen

25 Moll R, Franke WW, Schiller DL, Geiger B, Krepler R. The catalog of human cytokeratins: patterns of expression in normal epithelia, tumors, and cultured cells. Cell 1982;31: 11-24.

26 Quinlan RA, Schiller DL, Hatzfeld M, Achtstätter T, Moll $\mathrm{R}$, Jorcano JL, et al. Patterns of expression and organization of cytokeratin intermediate filaments. Ann NY Acad Sci 1985;455:282-306.

27 Gordon JI, Hermiston ML. Differentiation and self-renewal in the mouse gastrointestinal epithelium. Curr Opin Cell Biol 1994;6:795-803.

28 Quaroni A, Calnek D, Quaroni E, Chandler JS. Keratin expression in rat intestinal crypt and villus cells. $\mathcal{F}$ Biol Chem 1991;266:11923-31.

29 Calnek D, Quaroni A. Changes in keratin expression during fetal and postnatal development of intestinal epithelial cells. Biochem $\mathcal{F}$ 1992;285:939-46.

30 Calnek D, Quaroni A. Differential localization by in situ hybridization of distinct keratin mRNA species during intestinal epithelial cell development and differentiation Differentiation 1993;53:95-104.

31 Nardelli J, Bara J, Rosa B, Burtin P. Intestinal metaplasia and carcinomas of the human stomach: an immunohistological study. F Histochem Cytochem 1983;31:366-75.

32 Moll R, Zimbelmann R, Goldschmidt MD, Keith M, Laufer $\mathrm{J}$, Kasper $\mathrm{M}$, et al. The human gene encoding cytokeratin 20 and its expression during fetal development and in gastrointestinal carcinomas. Differentiation 1993;53:75-93.

33 Correa P. A human model of gastric carcinogenesis. Cancer Res 1988;48:3554-60.

34 Correa P. Human gastric carcinogenesis: a multistep and multifactorial process: First American cancer society award lecture on cancer epidemiology and prevention. Cancer Res 1992;52:6735-40.

35 Correa P. Helicobacter pylori and gastric carcinogenesis. Am f Surg Pathol 1995;19(Suppl 1):S37-43

36 Miettinen M. Keratin 20: immunohistochemical marker for o gastrointestinal, urothelial, and Merkel cell carcinomas. Mod Pathol 1995;8:384-8.

37 Tosi P, Filipe MI, Baak JPA, Luzi P, Santopietro R, Miracco N $\mathrm{C}$, et al. Morphometric definition and grading of intestinal metaplasia. F Pathol 1990;161:201-8.

38 Tosi P, Filipe MI, Luzi P, Miracco C, Santopietro R, Lio R, et al. Gastric intestinal metaplasia type III cases are classified as low-grade dysplasia on the basis of morphometry. $\mathcal{F} \mathbb{E}$ Pathol 1993;169:73-8.

39 Antonioli DA. Precursors of gastric carcinoma: A critical review with a brief description of early (curable) gastric cancer. Hum Pathol 1994;25:994-1005. 